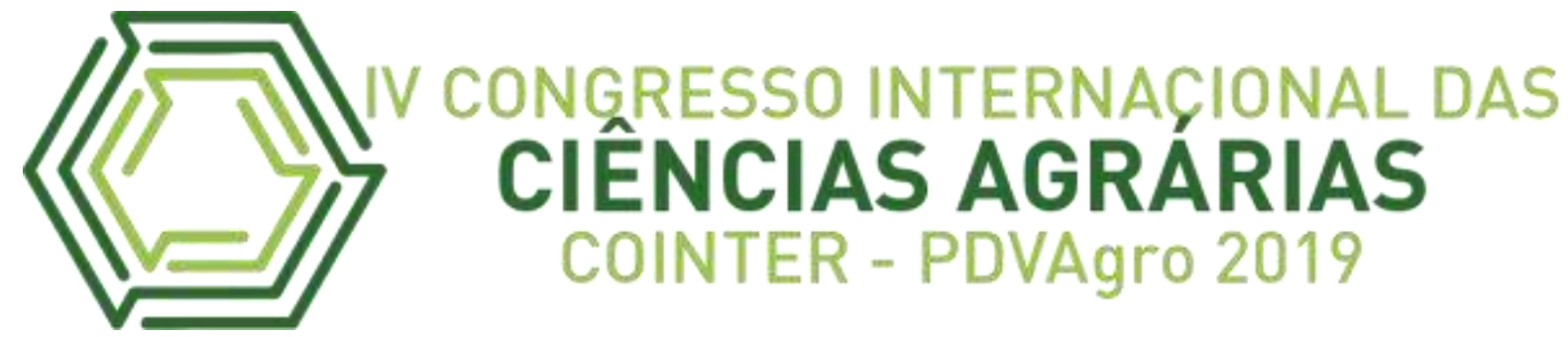

\title{
FUNGOS ASSOCIADOS A SECA DOS FRUTOS DO AÇAÍ (Euterpe oleracea Mart.) NO ESTADO DO PARÁ
}

\author{
HONGOS ASOCIADOS CON LA FRUTA ACAI (Euterpe oleracea Mart.) EN EL \\ ESTADO DE PARÁ
}

\section{FUNGI ASSOCIATED WITH THE AÇAI FRUIT (Euterpe oleracea Mart.) AT THE STATE OF PARÁ}

\author{
Apresentação: Comunicação Oral
}

Brendo Wilson da Silva Lima ${ }^{1}$; Géssica Jacira Trindade de Souza ${ }^{2}$; Kamila Teixeira de Cristo Ribeiro $^{3}$ Antônio Elison da Silva ${ }^{4}$; Kézia Ferreira Alves ${ }^{5}$

DOI: https://doi.org/10.31692/2526-7701.IVCOINTERPDVAgro.2019.0165

\begin{abstract}
Resumo
A região amazônica proporciona condições favoráveis para o desenvolvimento de doenças, por ter um clima com temperatura e umidade elevadas. Dentre as palmeiras, a espécie Euterpe oleracea, conhecido popularmente como açaizeiro, possui grande potencial para as indústrias alimentícia, artesanal e medicinal, sendo a polpa comercializada a nível internacional. Entretanto, a Seca dos Frutos é um exemplo de doença da cultura do açaizeiro que vem incidindo em intensidades crescentes e variáveis a cada ano em plantios nos períodos de safra e entressafra. O fungo Colletotrichum sp. incide sobre o principal produto comercializado, reduzindo o número de frutos sadios por cachos e o rendimento de polpa. O presente trabalho objetivou realizar a diagnose em campo e identificar fitopatógenos associados a seca dos frutos do açaizeiro, oriundos de municípios produtores no Estado do Pará. A diagnose se deu por meio da coleta de frutos de açaizeiro maduros apresentando lesões, em plantios nativos de várzea, em duas propriedades no Município de São Domingos do Capim, e em plantios de terra firme no município do Moju-PA. Estas amostras foram encaminhadas ao Laboratório de Microbiologia do Instituto Federal do Pará - Campus Castanhal para procedimento de esporulação e isolamento in vivo. Os frutos foram mantidos em ambiente de câmara úmida por 24h para estimular a esporulação, foi realizado o isolamento direto utilizando placas de Petri com meio de cultivo Batata-Dextrose-Ágar (BDA). Nas observações morfoculturais foi possível distinguir colônias, sendo a primeira de coloração branca e uma segunda colônia de cor verde escura; após 7 dias de incubação as colônias apresentaram colorações acinzentada e cinza enegrecido, respectivamente. Por meio de observações microscópicas a primeira colônia, apresentou hifas septadas e conídios cilíndricos ovoides com ápices arredondados,
\end{abstract}

\footnotetext{
${ }^{1}$ Agronomia, IFPA - Campus Castanhal, brendo199822@gmail.com

${ }^{2}$ Agronomia, FPA - Campus Castanhal, gesstrind@gmail.com

${ }^{3}$ Agronomia, IFPA - Campus Castanhal, marcosalcantara958@gmail.com

${ }^{4}$ Agronomia, IFPA - Campus Castanhal, elisonsilvaCDP@gmail.com

${ }^{5}$ Doutora em Fitotecnia, IFPA - Campus Castanhal, kezia.alves@ifpa.edu.br
} 
característicos dotaxa Colletotrichum, agente etiológico da seca dos frutos. Entretanto, a segunda colônia apresentou hifas septadas pigmentadas, conídios ovoides assimétricos com três septações transversais, células com coloração que varia do marrom-pálido a marrom-escuro com uma das células maior que as demais dando um aspecto de curvatura, característico do fungo dematiáceo Curvularia. Este é o primeiro registro da associação dos taxa Curvularia sp. ao fungo Colletotrichum sp., o qual poderá incrementar a ação do patógeno principal, mas as pesquisas deverão avançar no conhecimento da etiologia dos isolados catalogados no município de Moju, pois ainda não há técnicas de controle validadas para o manejo da seca dos frutos do açaizeiro.

Palavras-Chave: Açaizeiro; Doença; Fungos.

\section{Resumen}

La región amazónica ofrece condiciones favorables para el desarrollo de enfermedades, ya que tiene un clima con altas temperaturas y humedad. Entre las palmeras, la especie Euterpe oleracea, conocida popularmente como açaizeiro, tiene un gran potencial para las industrias alimentaria, artesanal y medicinal, siendo la pulpa que se vende internacionalmente. Sin embargo, la sequía de la fruta es un ejemplo de una enfermedad del cultivo de acaí que se ha centrado en intensidades crecientes y variables cada año en las temporadas de siembra y cosecha. El hongo Colletotrichum sp. se enfoca en el producto comercializado principal, reduciendo la cantidad de frutas saludables por racimo y el rendimiento de pulpa. El presente trabajo tuvo como objetivo realizar el diagnóstico de campo e identificar fitopatógenos asociados con la sequía de las frutas de açaí, provenientes de municipios productores en el Estado de Pará. En dos propiedades en el municipio de São Domingos do Capim - PA, y en plantaciones de tierra firme en el municipio de Moju - PA. Estas muestras fueron enviadas al Laboratorio de Microbiología del Instituto Federal de Pará - Campus Castanhal para un procedimiento de esporulación y aislamiento in vivo. Las frutas se mantuvieron en un ambiente de cámara húmeda durante $24 \mathrm{~h}$ para estimular la esporulación. El aislamiento directo se realizó usando placas de Petri con medio de cultivo de papa-dextrosa-agar (BDA). En las observaciones morfoculturales fue posible distinguir colonias, siendo la primera de coloración blanca y una segunda colonia de color verde oscuro. Después de 7 días de incubación, las colonias mostraron una coloración grisácea y gris negruzca, respectivamente. Mediante observaciones microscópicas, la primera colonia presentó hifas septadas y conidios cilíndricos ovoides con vértices redondeados, característicos de la tasa de Colletotrichum, el agente etiológico de la sequía de frutos. Sin embargo, la segunda colonia presentaba hifas septadas pigmentadas, conidias ovoides asimétricas con tres tabiques transversales, células con un color que varía del marrón pálido al marrón oscuro con una de las células más grandes que las otras dando un aspecto de curvatura, característica del hongo Curvularia dematia. Este es el primer registro de la asociación de taxones Curvularia sp. al hongo Colletotrichum sp., que puede aumentar la acción del patógeno principal, pero la investigación debe avanzar en el conocimiento de la etiología de los aislamientos catalogados en el municipio de Moju, ya que no existen técnicas de control validadas para el manejo de la sequía de árboles de açaí.

Palabras Clave: Açaí; Enfermedad; Hongos.

\section{Abstract}


The Amazon region provides favorable conditions for the development of diseases, as it has a climate with high temperature and humidity. Among palm trees, the species Euterpe oleracea, popularly known as açaízeiro, has great potential for the industries food, artisanal and medicinal, being the pulp sold internationally. However, the fruit drought is an example of a disease of the açaí crop that has been focusing on increasing and varying intensities each year in sowing and harvesting seasons. The fungus Colletotrichum sp. focuses on the main marketed product, reducing the number of healthy fruits per bunch and the pulp yield. The present work aimed to perform the field diagnosis and to identify phytopathogens associated with the drought of the acai fruits, coming from producing municipalities in the State of Pará. In two properties in the municipality of São Domingos do Capim-PA, and in solid ground plantations in the municipality of Moju-PA. These samples were sent to the Microbiology Laboratory of the Federal Institute of Pará - Campus Castanhal for sporulation and isolation procedure in vivo. The fruits were kept in a humid chamber environment for 24 hours to stimulate sporulation. Direct isolation was performed using Petri dishes with Potato-Dextrose-Agar (BDA) culture medium. In the morpho cultural observations it was possible to distinguish colonies, being the first one of white coloration and a second colony of dark green color; After 7 days of incubation the colonies showed grayish and blackish gray color, respectively. By microscopic observations the first colony presented septate hyphae and ovoid cylindrical conidia with rounded apexes, characteristic of the Colletotrichum rate, the etiological agent of fruit drought. However, the second colony presented pigmented septate hyphae, asymmetric ovoid conidia with three transverse septations, cells with a color ranging from pale brown to dark brown with one of the cells larger than the others giving a curvature aspect, characteristic of the Curvularia dematia fungus. This is the first record of the association of taxa Curvularia sp. to the fungus Colletotrichum sp., which may increase the action of the main pathogen, but research should advance the knowledge of the etiology of the isolates cataloged in the municipality of Moju, because there are no validated control techniques for the management of açaí fruit drought.

Keywords: Acai tree; Disease; Fungi. 


\section{Introdução}

Palmeira pertencente à família Arecacea a espécie Euterpe oleracea Mart., popularmente conhecido como açaí, possui grande potencial para a indústria alimentícia, artesanal e medicinal. A polpa oriunda de seus frutos é considerada como um dos principais alimentos das populações interioranas da região amazônica, seu local de origem (MARINHO, 2013).

É na região Norte do Brasil onde se concentra a produção mais expressiva de açaí, sendo os estados do Pará e Amazonas responsáveis por 87,5\% do total. O Pará é o maior produtor mundial de açaí, tendo dobrado sua produção nos últimos 10 anos, período no qual tornou-se o maior exportador brasileiro do fruto. Atualmente esse potencial econômico tem se estendido para o agronegócio, incluindo seu aproveitamento econômico integral (CONAB, 2019).

Com a expansão da cultura a busca por maior produção de açaí, tem estimulado o surgimento de áreas de exploração intensiva da planta. Neste momento de transição surgem inúmeras problemáticas que acompanham os plantios em monocultura, entre as quais, proporcionar condições favoráveis para o desenvolvimento de doenças, ocasionando a diminuição da produtividade esperada (ZIMMERMANN, 2009; ALVES, 2017).

Neste contexto, tendo em vista o potencial econômico do açaizeiro, este estudo objetiva realizar a diagnose em campo e identificar fitopatógenos associados a seca dos frutos do açaizeiro, oriundos de municípios produtores no Estado do Pará.

\section{Fundamentação Teórica}

O açaizeiro pode se desenvolver em diferentes ambientes como várzea, igapó e terra firme, isto porque apresenta condições adaptativas ao meio. Encontrada em países da América do Sul (Brasil, Venezuela, Colômbia, Equador, Suriname e Guianas), América Central (Trinidade) e América do Norte (Panamá) (HENDERSON; GALEANO, 1996; TROPICOS, 2018).

Porém, de acordo com Oliveira et al., (2015) é na região Amazônica brasileira, que o açaizeiro ocorre espontaneamente e em maior densidade populacional, tendo como centro de origem e diversidade genética a região estuarina do rio Amazonas, distribuindo-se em abundância. O Estado do Pará corresponde a sua principal área de dispersão os ambientes de várzea e igapó onde se concentra compondo ecossistemas de floresta natural ou em forma de maciços conhecidos como açaizais (NOGUEIRA, 2005). 
A demanda comercial por açaí tem crescido graças à divulgação das qualidades nutricionais da polpa dos frutos em outros estados do Brasil e até mesmo no mercado internacional. Obtido pela maceração de seus frutos seu suco e conhecido por açaí, é comercializado in natura, como polpa congelada, pasteurizada e na forma de mix, sendo o produto mais rentável. O açaí é considerado um alimento completo, contendo altos teores de lipídeos e fibras, além de apresentar proteínas, minerais como o cálcio, magnésio, potássio, níquel, manganês, cobre, boro e cromo, além de vitaminas B1 e E (OLIVEIRA, 2015).

Desta forma busca-se a otimização de produção desta matéria-prima, no entanto, principalmente os cultivos racionais ou monocultivos, são acometidos por problemas fitossanitários (LIMA, 2019).

Enfermidades de plantas cultivadas possuem expressiva importância na história, pois são responsáveis por grandes prejuízos econômicos e sociais à humanidade. As doenças, em sua maioria, são classificadas ou diagnosticadas através dos sintomas característicos de patógenos que podem ser microrganismos ou condições abióticas (BERGAMIM FILHO, AMORIM \& REZENDE, 2011).

Mediante a importância dos fungos fitopatogênicos relacionados ao açaizeiro, os trabalhos existentes tratam de isolamentos rotineiros de laboratório, com identificação morfológica de Colletotrichum spp., Fusarium spp. em frutos de açaí e fase de viveiro, além de ocorrências de Penicillium e Aspergillus em sementes armazenadas (BATISTA, et al. 2007; NASCIMENTO; MORAES, 2011).

Dentre as doenças que vem chamando a atenção de produtores no Estado do Pará está a Seca dos Frutos do Açaizeiro, ou antracnose, a qual foi relatada pela primeira vez por Batista et al. (2007) em frutos verdes e maduros coletados em Muaná - PA, e vem incidindo em intensidades variáveis a cada ano em plantios de diversas localidades do estado do Pará.

Frutos de açaí que são acometidos pelo agente etiológico Colletotrichum spp. apresentam lesões com pequenas manchas de coloração chocolate a negra, de aspecto seco e enrugado com bordo definido sobre a superfície do fruto verde e/ou maduro. Quando estes frutos estão sob condições ambientais favoráveis, podem apresentar intensa esporulação alaranjada, necrosando parcialmente ou totalmente os frutos, avançando da casca para o interior da polpa do fruto, ocasionando a seca de frutos, que podem cair ou ficar aderidos ao cacho de açaí (ALVES et al., 2017). 


\section{Metodologia}

As análises de cunho qualitativo foram realizadas em o período de um (01) ano, entre os meses de agosto de 2018 e agosto de 2019. O mesmo constituiu-se em duas etapas:

\section{$1^{\circ}$ Etapa: Coleta de Amostras em Campo}

As coletas foram realizadas no município de São domingos do Capim, no nordeste paraense, distante $150 \mathrm{~km}$ da capital Belém, situada sob as coordenadas de Latitude: $1^{\circ} 40^{\prime} 33^{\prime \prime}$ Sul e Longitude: $47^{\circ}$ 45' 57" Oeste. E também no município de Moju, também no nordeste paraense, distante $130 \mathrm{~km}$ de Belém, situada sob as coordenadas de Latitude: $1^{\circ} 53^{\prime} 5^{\prime \prime}$ Sul, Longitude: $48^{\circ} 45^{\prime} 55^{\prime \prime}$ Oeste. Ambos os municípios possuem propriedades produtoras de fruto do açaizeiro.

Para a realização desta investigação foram visitadas propriedades onde se encontram a espécie nativa Euterpe oleracea, e propriedades em terra firme com a variedade BRS-Pará, sendo realizada a coleta de amostras sintomáticas em duas localidades, sendo elas: uma propriedade familiar no município de São Domingos do Capim-PA e uma propriedade familiar no município de Moju-PA.

A coleta do material vegetal foi realizada no período da safra, correspondente ao segundo semestre de 2018 e também no início do mês de janeiro de 2019, que consistiu na coleta de frutos sintomáticos para análise, com o auxílio de técnicos da Emater e produtores locais que relataram os sintomas da seca, ajudaram na diagnose a campo bem como na coleta dos frutos sintomáticos retirados diretamente dos cachos.

\section{$2^{\circ}$ Etapa: Análises Laboratoriais}

Após a coleta as amostras foram armazenadas em sacos plásticos, identificadas e encaminhadas ao laboratório de Microbiologia de Alimentos do Instituto Federal de Educação, Ciência e Tecnologia do Pará, Campus Castanhal, localizado na Mesorregião do Nordeste Paraense, situado à margem da BR 316, Km 62, latitude: $01^{\circ} 17^{\prime} 51,7^{\prime \prime S}$, longitude: 47 57' 03,3" W, município de Castanhal-PA.

Na recepção laboratorial, organizaram-se os frutos separadamente de acordo com o local de origem, estes sendo higienizados com água corrente e postos em papel toalha para a retirada do excesso de água para indução da esporulação em ambiente de câmara úmida utilizando-se gerbox em período de vinte e quatro (24) horas (Figura 1). Após desenvolvimento da colônia realizou-se o isolamento direto em placas de Petri vertidas com meio de cultivo Batata- 
Dextrose-Ágar (BDA), e submetido a BOD de Germinação à $25^{\circ} \mathrm{C}$ (Demanda Química de Oxigênio) onde foram mantidos em observação por 7 dias.

Figura 1: Frutos maduros no cacho apresentando esporulação do fungo (A); Furtos de açaí em abiente de câmara úmida (B); Cultivo fúngico em estufa BOD à $25^{\circ} \mathrm{C}(\mathrm{C})$.

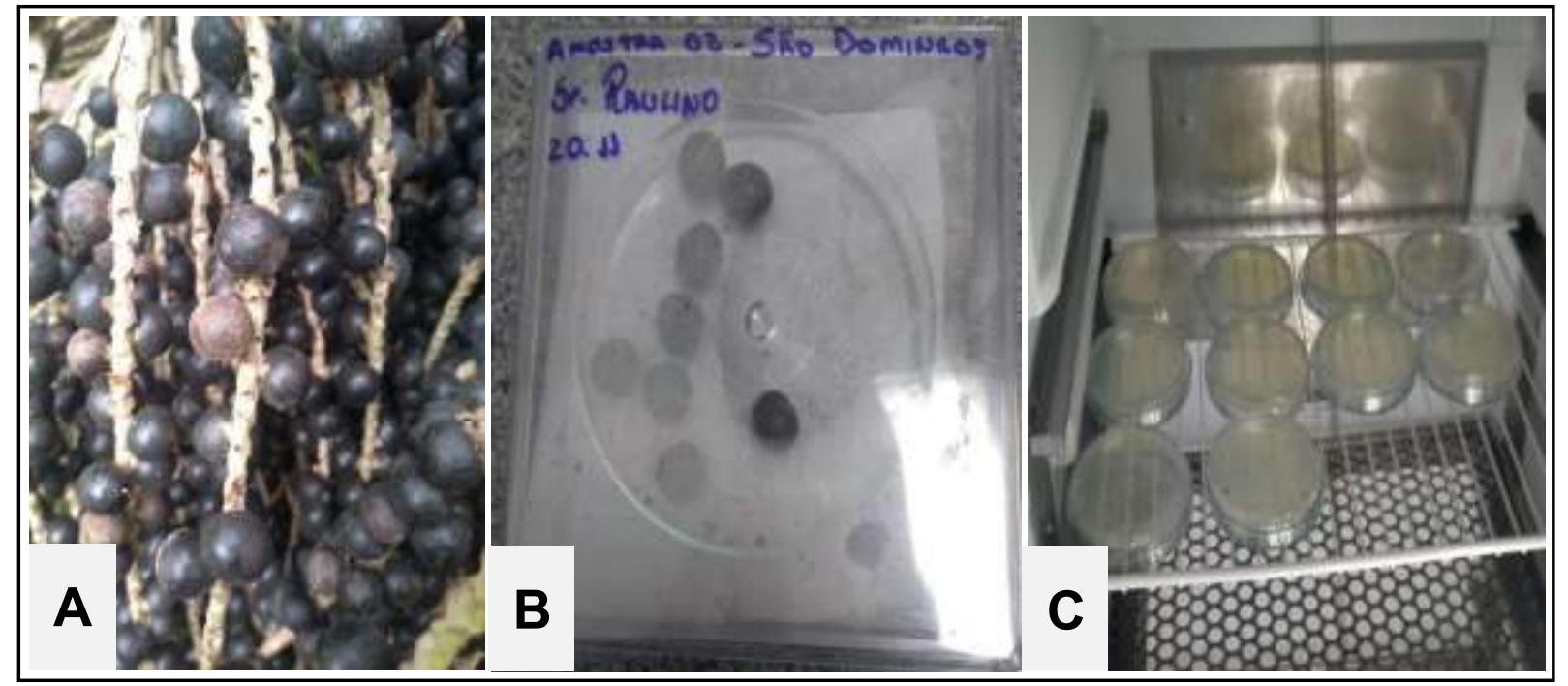

Fonte: LIMA (2019)

A identificação morfológica foi realizada a partir de observações da morfologia macroscópica e microscópicas da colônia, onde ao término do período de observação realizouse a confecção de lâminas de identificação aos respectivos isolados as quais foram análisadas sob micróscopio óptico de luz. Assim efetivou-se uma nova repicagem para obtenção de desenvolvimento de colônias empregadas ao teste de patogenicidade, com intuito de confirmar a patogenicidade destes organismos sobre o hospedeiro. Frutos sadios foram submetidos a quatro injúrias com o auxilio de uma almofada de alfinetes desinfestados com cerca de $1 \mathrm{~mm}$ de profundidade, sendo inoculados com $10 \mu 1$ da suspensão de conídios na concentração de $1 \times 10^{6}$ conídios/ml

Após a inoculação, os frutos foram mantidos por 24 horas sob câmara úmida em gerbox contendo quatro camadas de papel toalha umedecida com água destilada esterilizada. O contato dos frutos com a umidade foi evitado pela colocação dos frutos sobre grades plásticas. A testemunha consistiu de frutos com ferimentos tratados com água destilada esterilizada e inoculados com o patógeno. As gerbox com os frutos ficaram mantidas sob temperatura ambiente. Este procedimento foi repetido para ambos os isolados à serem inoculados. 
Figura 2: Teste de patogenicidade para Colletotrichum sp. em frutos verdes de açaí.

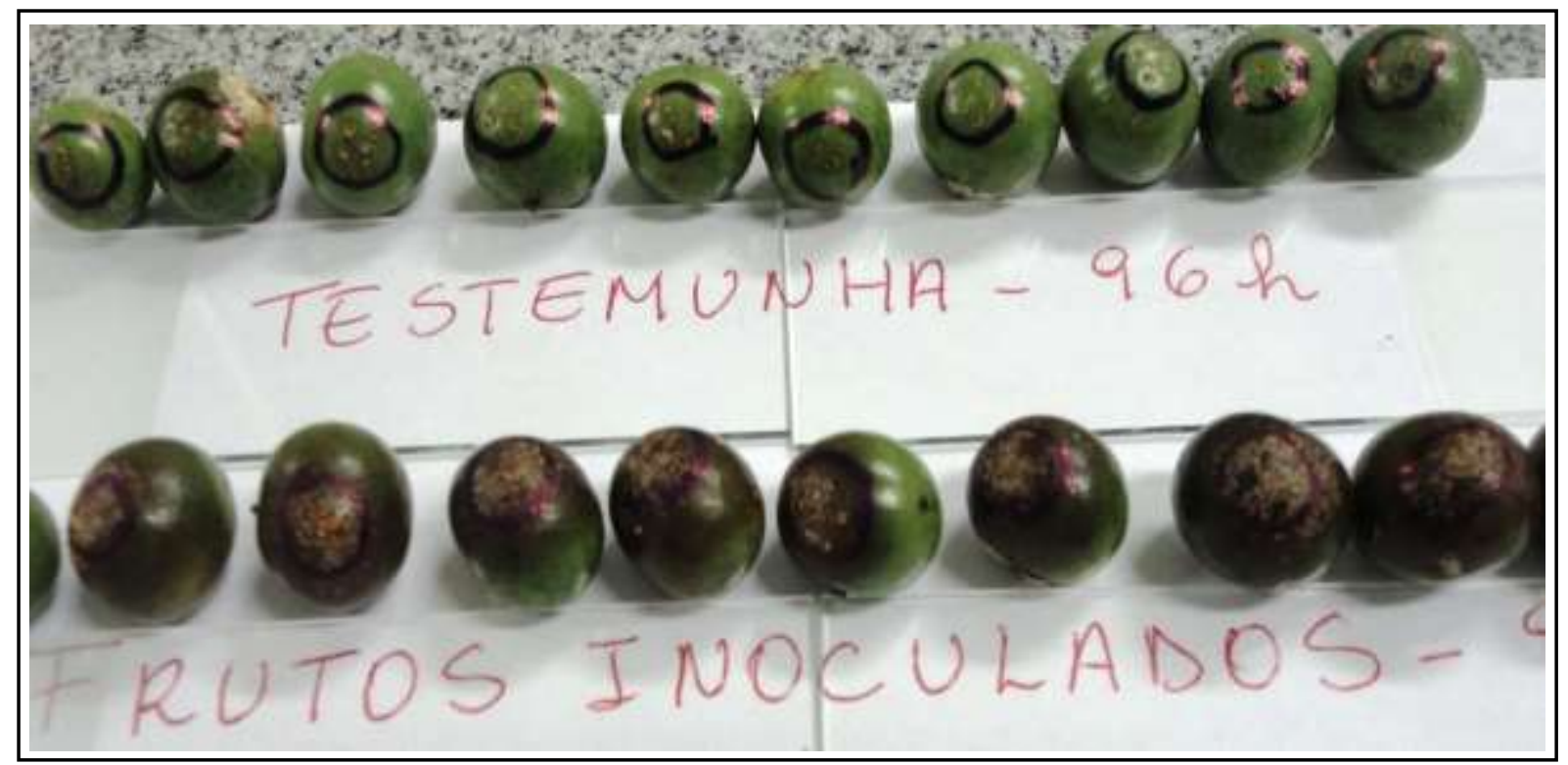

Fonte: ALVES (2019)

Figura 3: Teste de patogenicidade para Curvularia sp. em frutos verdes de açaí em gerbox.

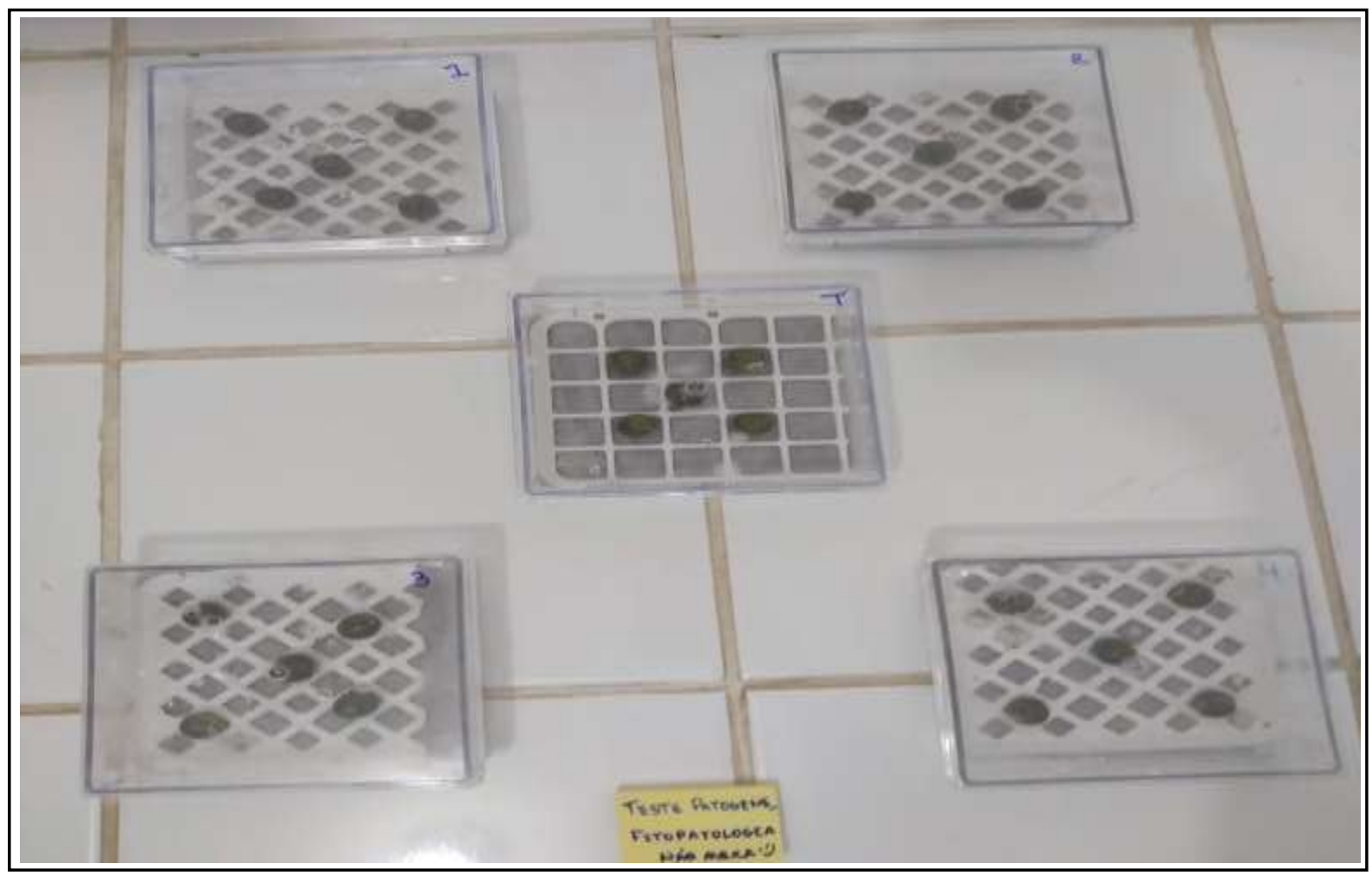

Fonte: LIMA (2019) 
Passada 96 horas de incubação, fora retirada a câmara úmida e posteriormente dando prosseguimento nas análises morfológicas das estruturas fúngicas presentes nos frutos, com o preparo de lâminas para observação através de microscopia.

\section{Resultados e Discussão}

Constatou-se a singularidade entre duas distintas colônias em desenvolvimento. Sendo o crescimento micelial inicial de coloração branca em um dos isolados e verde escura em outro, ao término do período de incubação as colônias apresentaram colorações acinzentada (Figura 4) e cinza enegrecido (Figura 5).

Através das análises microscópicas observou-se que os isolados de coloração cinza, apresentam hifas septadas, conidiomas acervulares, não setosos, conídios unicelulares, cilíndricos ovoides ou oblongos às vezes curvados com ápices arredondados, caracterizados segundo Luz (2011), como teleomorfo Glomerella, e anamórfica Gloesporium, característicos do gênero Colletotrichum (Figura 4). Convergindo com o descrito na literatura que cita o gênero apresentando colônia de coloração cinza escura, no seu verso e coloração enegrecida. Pertence ao Filo Ascomycota, ordem Phyllachorales e família Phyllachoraceae, sendo suas características morfológicas que o identificam são a conidiomata acervular com hifas estéreis de coloração escura, não ramificada, com parede espessa e conídios oblongos. (SOUZA, 2018)

De acordo com Junqueira et al., (2005) os danos causados por C. gloeosporioides são mais evidentes em plantas adultas, mas também atacam na fase de viveiro. $\mathrm{O}$ fungo coloniza tanto os tecidos novos e brotações, quanto os frutos, mantendo-se em estado latente ou quiescente sem a manifestação de algum sintoma até que as condições de temperatura, umidade ou fisiológica da planta se tornem favoráveis. Portanto a incidência de antracnose em mudas pode limitar o cultivo (OLIVEIRA et. al., 2015).

Quando a ocorrência do patógeno dá-se em viveiro para evitar a ocorrência deste sintoma deve-se adotar práticas como a adubação correta, a manutenção em locais bem arejados, tomando espaçamentos suficientemente largos evitando o excesso de umidade (YAMANAKA, 2012)

Já os sintomas de antracnose nos frutos são caracterizados por manchas necróticas que avançam sob a casca alcançando o interior onde se localiza a polpa, levando ao apodrecimento generalizado, sintoma este que ainda não possui controle efetivo e que compromete o desempenho de processamento do fruto por minimizar seu rendimento de polpa (BATISTA et 
al., 2007)

Figura 4: Crescimento cultural em placa de petri após 7 dias de incubação em BOD (A); Microscopia apresentando conídios de Colletotrichum spp. (B);

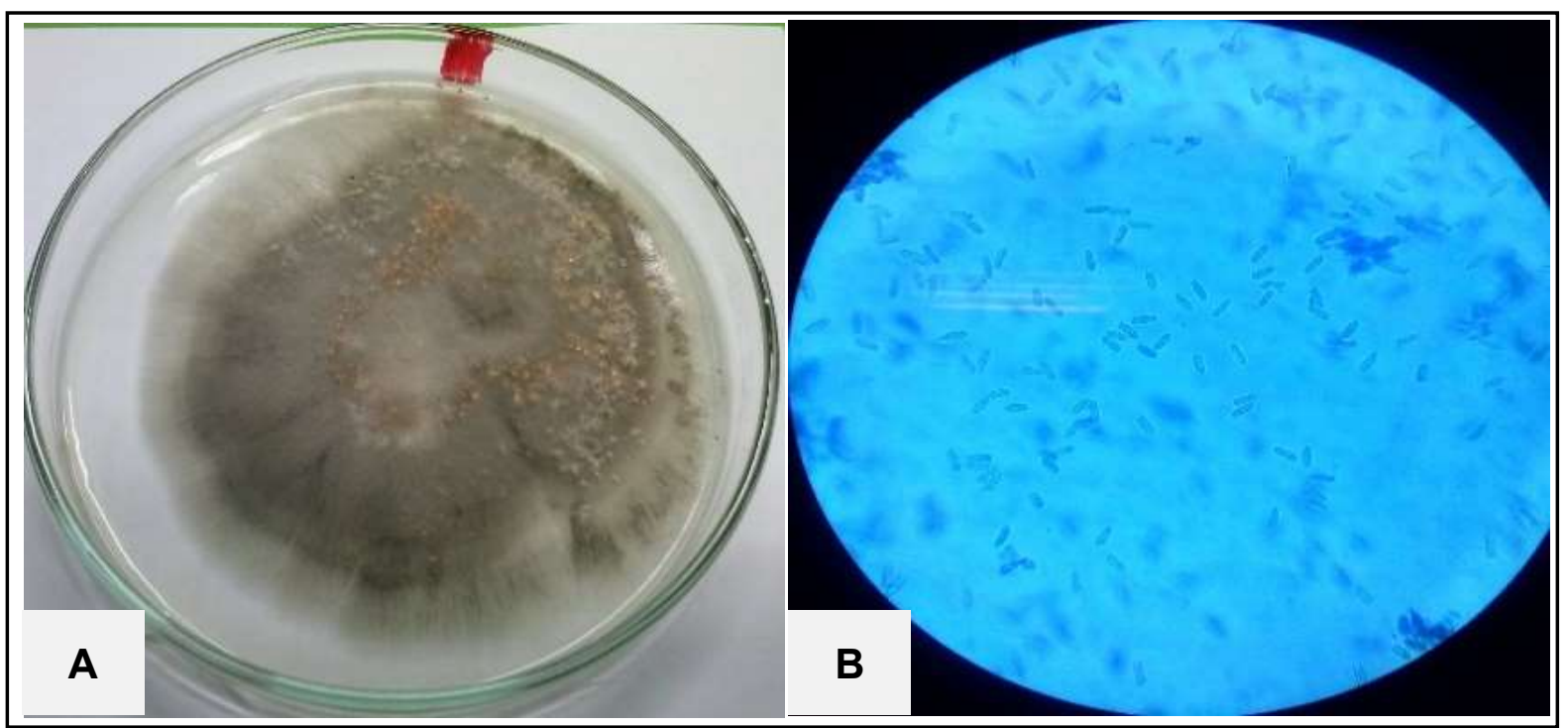

Fonte: LIMA (2019)

Figura 5: colônia fúngica após 7 dias de incubação em estufa BOD (A); aglomerado de esporos característicos de Curvularia spp.(B)

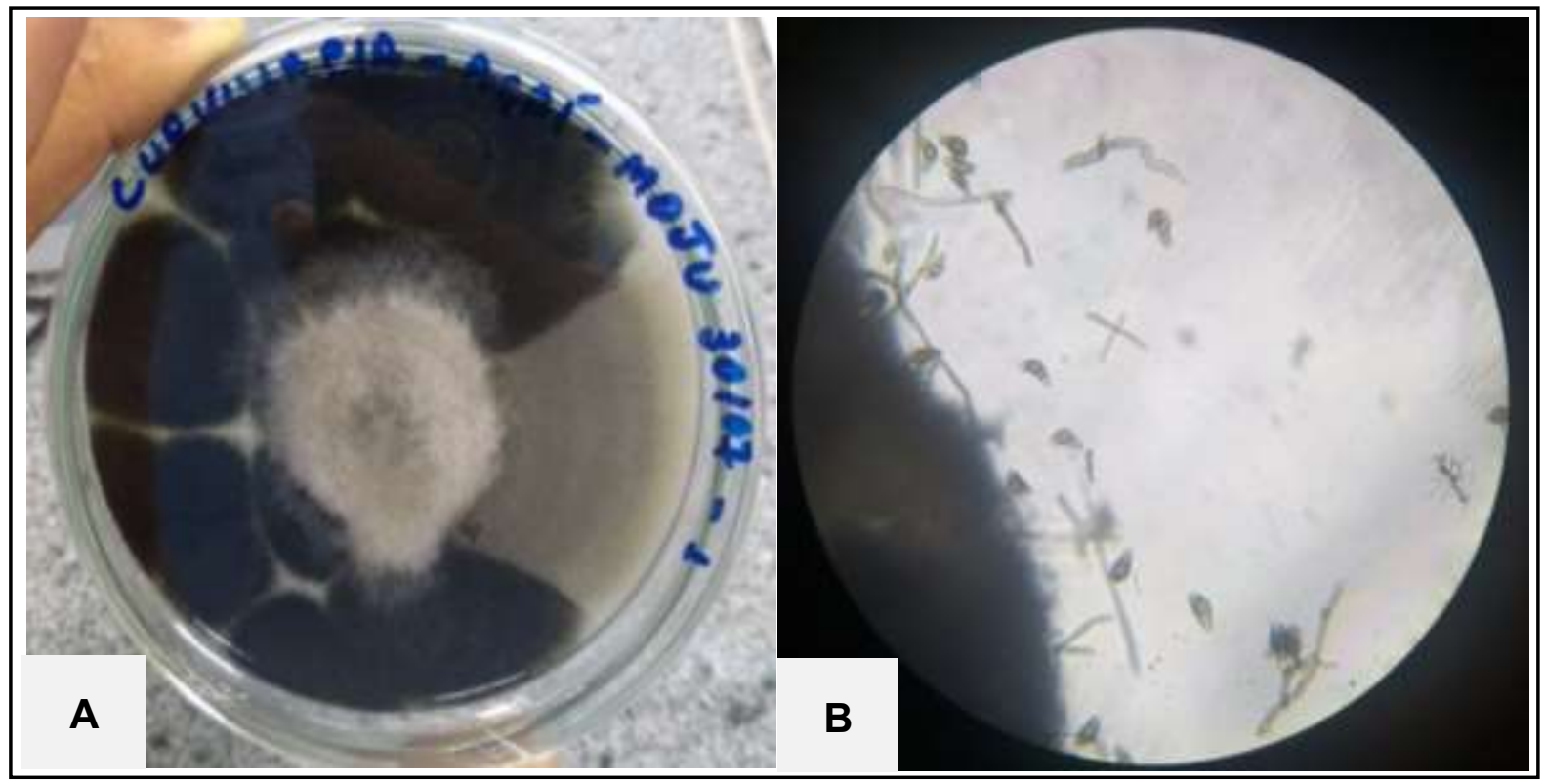

Fonte: LIMA (2019) 
$\mathrm{O}$ isolado apresentando a coloração cinza enegrecido, notou-se a presença de hifas septadas pigmentadas, conídios com septos transversos, escuros, com as células das extremidades mais claras, com quatro células, uma célula mediana maior que as demais, crescimentos conidiais apicais e laterais, com célula-mãe politrética, conidióforos macronemáticos, com crescimento subterminal, características essas do fungo dematiáceo do gênero Curvularia (LUZ, 2011).

O gênero Curvularia é composto por mais de 40 táxones que se distinguem por diferenças mais ou menos evidentes na morfologia dos conídios, número de septos e aspectos culturais, esta variabilidade morfológica observada nestes fitopatógenos, levou as espécies a uma separação em três grupos, 'geniculata', 'lunata', e 'maculans', que se diferenciaram pelo formato dos conídios e o número de septos. Nos grupos lunata e maculans, ficaram alocadas as espécies com conídios de três ou mais células septos como e o caso do fungo identificado neste estudo (LIMA \& FURTADO, 2007).

Os sintomas da Curvularia podem se manifestar nas folhas, que se tornam amareladas e murchas, resultado da necrose dos bulbos, também apresentam manchas ovais de coloração marrom-escura nas folhas e frutos. De maneira geral, quando encontrado em vegetais superiores apresenta natureza endofítica, mas quando tem a capacidade de sobreviver ao sistema de defesa dos vegetais, são considerados fitopatogênicos. (MYCOBANK, 2010)

Santos (2003) destaca a patogenicidade deste fungo em folhas de Pupunha (Bactris gasipaes Kunth) e de Palmeira real (Archontophoenix sp.), no entanto este é o primeiro registro da associação da taxa de Curvularia sp. ao fungo Colletotrichum sp., o qual poderá incrementar a ação do patógeno principal, mas as pesquisas deverão avançar no conhecimento da etiologia dos isolados catalogados no município de Moju, pois ainda não há técnicas de controle validadas para o manejo da seca dos frutos do açaizeiro.

Faz-se necessário a verificação da expressiva gama de patógenos de interesse agronômico, levando em consideração que ainda existem poucos estudos sobre a variabilidade genética dos agentes que ocasionam enfermidades ao hospedar o pericarpo de frutos de açaizeiro, uma vez que estudos mais detalhados desse patossistema é de suma importância para a garantia da manutenção da sanidade nas áreas produtivas.

\section{Conclusões}

Há ocorrência do fungo Colletotrichum spp. nos municípios de São Domingos do Capim 
e Moju. No entanto, neste último foi possível isolar e identificar o fungo Curvularia sp. associado às colônias de Colletotrichum corroborando na manifestação dos sintomas de seca dos frutos do açaizeiro nos plantios examinados. 


\section{Referências}

ALVES, K. F.; MESSIAS, S. D. R.; ARAÚJO, M., NASCIMENTO, S.; CARVALHO, E. D. A. Seca dos frutos no açaí (Euterpe oleracea Mart.) no estado do Pará, Brasil. In Embrapa Recursos Genéticos e Biotecnologia-Resumo em anais de congresso. In: CONGRESSO BRASILEIRO DE FITOPATOLOGIA, 50, 2017, Uberlândia. SBF, 2017.

BATISTA, T. F. C.; OLIVEIRA, F. C.; TABOSA, S. A. S.; NUNES, M. A. N. Ocorrência de Antracnose em Frutos de Açaí, Euterpe oleracea, em Muaná, Pará. Fitopatologia Brasileira, Brasília, v.32, n.4, 2007.

BERGAMIN, F. A.; AMORIN, L.; REZENDE, J. A. M. 2011. Importância das doenças de plantas. In: AMORIN, L.; Rezende, J.A.M.; Bergamin Filho, A.; (Ed.) Manual de Fitopatologia: princípios e conceitos. São Paulo: Agronômica Ceres. p. 19-36.

CONAB. 2019. Relatório: Corredores de escoamento da produção agrícola, Análise Mensal. Disponível em: <file:///E:/Downloads/AcaiZ-ZAnaliseZMensalZZ-ZmarcoZ2019_1.pdf> Acesso em: 21 de Set. de 2019.

HENDERSON, A.; GALEANO, G. Euterpe, Prestoea, and Neonicholsonia (Palmae). Flora Neotropica, 72, 1-89. (1996). Disponível em: <http://www.jstor.org/stable/439387. Acesso em: 29 de Jul. de 2019.

JUNQUEIRA, N. T. V.; BRAGA, M. F.; SHARMA, R. D.; PEIXOTO, J. R.; JUNQUEIRA, L. P. Manejo das principais doenças do maracujazeiro. In: POLTRONIERI, L. S. et al. (Org.) Pragas e doenças de cultivos amazônicos. Belém, PA: Embrapa Amazônia Oriental. p. 157-190. 2005.

LUZ, W. C. Micologia Avançada: Taxonomia de fungos anamórficos - I. Hifomicetos. Passo Fundo: Rapp, 2011. 400 p. 3 v.

LIMA, B. W. S.; ALVES, K. F.; SOUZA, G. T. de S. Colletotrichum sp., agente etiológico da Seca dos Frutos do Açaizeiro (Euterpe oleracea Mart.) no município de São Domingos do Capim - PA. $51^{\circ}$ Congresso Brasileiro de Fitopatologia. Recife - PE, 2019.

LIMA, A.; FURTADO, M. Espécies do Gênero Curvularia (Fungos Anamórficos: Hyphomycetes) na Ilha De Santiago, Cabo Verde. Anais Portugaliae Acta Biol. 22: 145-156 Lisboa, 2007

MARINHO, B. R.; MIRANDA I. P. A.; BARBOSA E. M.; Análise do Escoamento da Produção do Açaí (Euterpe Precatoria Mart.) no Estado do Amazonas. II Congresso de Iniciação Científica PIBIC/CNPq - PAIC/FAPEA, Manaus - 2013

MYCOBANK. 2010. Disponível em: <http://www.mycobank.org/BioloMICSServer.aspx? Link=T\&Rec=265873>. Acesso em: 10 jun. 2019.

NASCIMENTO, W. M. O.; MORAES, M. H. D. Fungos associados a sementes de açaí: Efeito da temperatura e do teor de água das sementes durante o armazenamento. Revista 
Brasileira de Sementes. Londrina, v.33, n.3 p.415-425, 2011.

NOGUEIRA, O. L, FIGUEIRÊDO, F.J. C; MULLER, A.A. Açaí. Embrapa Amazônia Oriental. Belém, Pará. 137p. (Sistemas de Produção, 4). 2005.

OLIVEIRA, M.; NETO, J. T. F.; QUEIROZ, J. A. L. Açaizeiro: cultivo e manejo para produção de frutos. In: Embrapa Amazônia Oriental-Artigo em anais de congresso (ALICE). In: ENCONTRO AMAZÔNICO DE AGRÁRIAS, 7., 2015, Belém, PA. Segurança alimentar: diretrizes para Amazônia. Belém, PA: UFRA, 2015.

OLIVEIRA, P. S., HERMÍNIO, M., de OLIVEIRA, M. T. B., de MACEDO, P. E. F., \& NOGUEIRA, S. (2015). Alternativas de controle da Antracnose em açaizeiro, causada por Colletotrichum gloesporioides. In Embrapa Acre-Resumo em anais de congresso (ALICE). In: CONGRESSO REGIONAL DE PESQUISA DO ESTADO DO ACRE; SEMINÁRIO DE INICIAÇÃO CIENTÍFICA DA UFAC, 24., 2015, Rio Branco. Anais., Rio Branco: CNPq; Ufac; Embrapa; Fapac; Ieval, 2015.

SANTOS, A. D., Bezerra, J. L., Tessmann, D. J., \& Poltronieri, L. S. Ocorrência de Curvularia senegalensis em pupunheira e palmeira real no Brasil. Embrapa Amazônia Oriental. Fitopatol. bras. V.28(2), mar - abr 2003

SOUZA, G. J. T.; ROSA, M. A. G.; TEIXEIRA, R. N. P.; RODRIGUES, M. G.; ALVES, K. F. Fitopatógenos Associados a Mancha Foliar em Mogno Africano (Khaya Ivorensis), no Municipio de Castanhal-Pa. Anais do Congresso Internacional das Ciências AgrariasCOINTER. In $3^{\circ}$ Congresso Internacional das Ciências Agrarias (PDV -Agro). João Pessoa $\mathrm{PB}, 2018$

TROPICOS. 2018. Euterpe oleracea Mart. Disponível em: <:http://www.tropicos.org/Name Page.aspx?nameid=2401358> . Acesso em 20 de Set. de 2019.

YAMANAKA, E. S. Cultivo, extração e beneficiamento do açaí orgânico. São Paulo, UNESP. 2012.

ZIMMERMANN, C. L. Monocultura e Transgenia: Impactos Ambientais e Insegurança Alimentar. Anais do Veredas do Direito, Belo Horizonte, v.6. n.12. p.79-100. Julho-Dezembro de 2009 